\title{
Effect of the degree of a diffuse phase transitions on the behavior of polarization switching processes and elastic properties in multicomponent ceramics based on PZT
}

\author{
A.V. Skrylev ${ }^{1}$, G.M. Akbaeva ${ }^{2}$, A.I. Burkhanov ${ }^{3}$, A.V. Sopit ${ }^{3}$, E.M. Panchenko ${ }^{2}$
}

${ }^{1}$ Institute of High Technologies and Piezotechnics Southern Federal University, 344090, Rostov-on-Don, Russia

${ }^{2}$ Research Institute of Physics Southern Federal University, 344090, Rostov-on-Don, Russia gakbaeva@mail.ru

${ }^{3}$ Volgograd State Technical University, 400005, Volgograd, Russia

The study of a number of ferroelectric-soft ceramics based on PZT shows that they exhibit properties characteristic of ferroelectrics-relaxors [1]. However, unlike relaxors they exhibit pronounced ferroelectric properties under certain conditions, as shown, for example, in [2]. Since multicomponent complex perovskite systems have structural disorder, the properties of such materials can exhibit features associated with the inhomogeneity of the phase state over a wide temperature range.

The purpose of this study is to investigate effect of the degree of a diffuse phase transitions on the behavior of polarization switching processes and elastic properties in multicomponent ceramics based on PZT:

$$
\begin{aligned}
& \text { 1. } 0.35 \mathrm{PbTiO}_{3}-0.21 \mathrm{PbZrO}_{3}-\mathrm{Pb}\left(\mathrm{Ni}_{1 / 3} \mathrm{Nb}_{2 / 3}\right) \mathrm{O}_{3}-\mathrm{Zn}_{1 / 3} \mathrm{Nb}_{2 / 3} \mathrm{O}_{3} \\
& \text { 2. } 0.36 \mathrm{PbTiO}_{3}-0.33 \mathrm{PbZrO}_{3}-\mathrm{Pb}(\mathrm{MgZn})_{1 / 3} \mathrm{Nb}_{2 / 3} \mathrm{O}_{3}-\mathrm{BaTiO}_{3}-\mathrm{SrZrO}_{3}
\end{aligned}
$$

in a wide temperature range, including the region of phase transitions between two polar phases and the main phase transition from the ferroelectric phase to the cubic phase.

Figure 1 presents temperature dependence of the effective dielectric constant $\varepsilon_{\text {eff }}^{\prime}=P / \varepsilon_{0} E$ ( $P$ - the polarization determined by Sawyer-Tower method, $E$ - the amplitude of the measuring field) in materials at frequency $1 \mathrm{~Hz}$ in wide range of temperatures of the diffuse phase transaction.
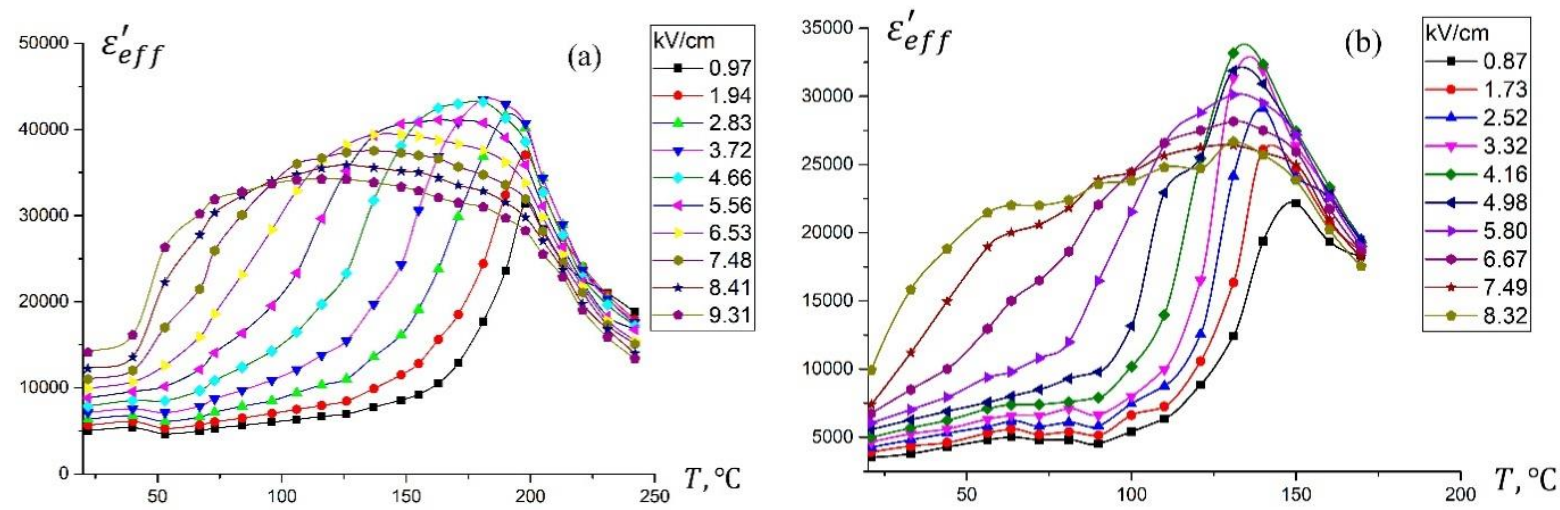

Figure 1. Temperature-frequency dependence $\varepsilon_{e f f}^{\prime}$, (a) - composition 1 and (b) composition 2.

1. A.A. Bokov, Z.-G. Ye, J. Mater. Sci. 41, 31 (2006).

2. A.V. Skrylev, A.I. Burkhanov, G.M. Akbaeva, A.E. Panich, Bull. Russ. Acad. Sci. Phys. 82, 372 (2018). 